\title{
Optic nerve sheath diameter in critically ill patients: nuances and interpretation
}

\author{
Amos Lal ${ }^{1 *}$ D, Kamal Kant Sahu², Ajay Kumar Mishra ${ }^{2}$ and Jamal Akhtar ${ }^{3}$
}

To the Editor,

We read with great attention the remarkable research letter by Yang and colleagues studying the utility of optic nerve sheath diameter (ONSD) in predicting sepsisassociated encephalopathy (SAE) (surrogate for raised intracranial pressure) in critically ill patients [1]. However, careful reading of the letter raises some concerns that could alter the interpretation of results and overall conclusion. It has been well known that the use of corticosteroids and/or sudden discontinuation can significantly increase the risk of intracranial hypertension and thereby alter the dimensions of the ONSD [2-4]. It has been hypothesized that the sudden withdrawal of corticosteroids can reduce the absorption of cerebrospinal fluid (CSF) and can cause increased resistance to the flow of CSF thereby resulting in intracranial hypertension [4]. Prolonged use of corticosteroids can also create a biochemical scenario similar to vitamin A toxicity with increased carotene levels [2]. This may in turn behave like pseudotumor cerebri and thus intracranial hypertension. It is important to know since many of the critically ill patients in the intensive care unit (ICU) require steroids for a plethora of reasons such as stress dose steroids for septic shock. Sepsis itself has been identified as a clinical state with deficiency of intrinsic corticosteroids. Authors while describing the baseline characteristics of patients should shed more light on this, if these patients in all 3 groups were matched in terms of steroid use.

Systemic hypertension itself could be an independent risk factor for increase in ONSD and has been studied in the past [5]. While presenting the baseline characteristics of the 3 groups studied by the authors, they have

\footnotetext{
*Correspondence: Lal.Amos@mayo.edu; manavamos@gmail.com 1 Department of Medicine, Division of Pulmonary and Critical Care Medicine, Mayo Clinic, Rochester, MN, USA

Full list of author information is available at the end of the article
}

omitted the important details specifically about the percentage of hypertensive patients (and baseline blood pressure values at the time of assessment of ONSD).

We wish to congratulate the authors for this remarkable work in the critical care setting to risk stratify patients with SAE with the help of ONSD. However, providing further details about the clinical status of the patients in this setting (such as blood pressure readings) and details of past medical background (steroid use and history of endocrinopathies) will provide readers of this journal with much needed clarity and further credibility to this outstanding work.

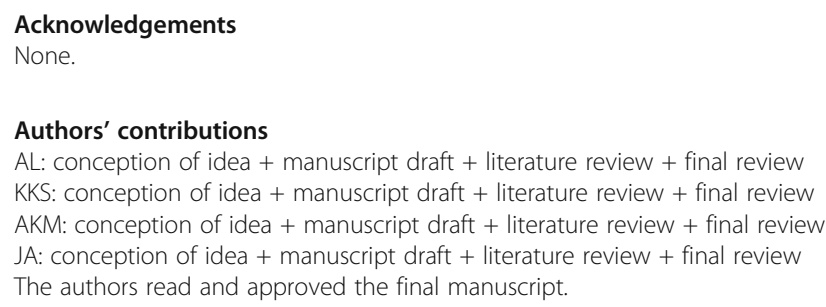

\section{Funding}

Not applicable.

\section{Availability of data and materials}

Not applicable.

\section{Ethics approval and consent to participate}

No IRB approval required.

\section{Consent for publication}

Not applicable.

\section{Competing interests}

Not applicable.

\section{Author details}

'Department of Medicine, Division of Pulmonary and Critical Care Medicine, Mayo Clinic, Rochester, MN, USA. ²Department of Medicine, Saint Vincent Hospital, Worcester, MA, USA. ${ }^{3}$ Department of Sleep Medicine, Montefiore Medical Center, Bronx, New York, NY, USA. 
Received: 26 May 2020 Accepted: 9 June 2020

Published online: 15 June 2020

\section{References}

1. Yang Z, Qin C, Zhang S, Liu S, Sun T. Bedside ultrasound measurement of optic nerve sheath diameter in patients with sepsis: a prospective observational study. Crit Care. 2020;24(1):235.

2. Walker $A E$, Adamkiewicz JJ. Pseudotumor cerebri associated with prolonged corticosteroid therapy. reports of four cases. Jama. 1964;188:779-84.

3. Leggio MG, Cappa A, Molinari M, Corsello SM, Gainotti G. Pseudotumor cerebri as presenting syndrome of Addisonian crisis. Ital J Neurol Sci. 1995; 16(6):387-9.

4. Shenouda S, Al-Farawi K, Dolan J, Flesher SL. "Idiopathic intracranial hypertension as a presenting sign of adrenal insufficiency." SAGE Open Med Case Rep. 2018;6:2050313×17753787. https://doi.org/10.1177/ $2050313 \times 17753787$.

5. Roque PJ, Barth L, Drachman D, WU T, LoVecchio F. 85 optic nerve ultrasound in the hypertensive patient. Ann Emerg Med. 2011;58(4):S206.

\section{Publisher's Note}

Springer Nature remains neutral with regard to jurisdictional claims in published maps and institutional affiliations. 